\title{
Physicochemical characterisation of combustion particles from vehicle exhaust and residential wood smoke Anette Kocbach ${ }^{1}$, Yanjun $\mathrm{Li}^{2}$, Karl E Yttri ${ }^{3}$, Flemming R Cassee ${ }^{4}$, Per E Schwarze ${ }^{1}$ and Ellen Namork*1
}

Address: ${ }^{1}$ Division of Environmental Medicine, Norwegian Institute of Public Health, P.O. Box 4404, N-0403 Oslo, Norway, ${ }^{2}$ Department of Physics, University of Oslo, Norway, ${ }^{3}$ Department for Chemical Analysis, Norwegian Institute for Air Research, Kjeller, Norway and ${ }^{4}$ Center of Environmental Health Research, National Institute for Public Health and the Environment (RIVM), Bilthoven, the Netherlands

Email: Anette Kocbach - anette.kocbach@fhi.no; Yanjun Li - yanjun.li@smn.uio.no; Karl E Yttri - key@nilu.no; Flemming R Cassee - f.cassee@rivm.nl; Per E Schwarze - per.schwarze@fhi.no; Ellen Namork* - ellen.namork@fhi.no

* Corresponding author

Published: 03 January 2006

Particle and Fibre Toxicology 2006, 3:1 doi:10.1 186/1743-8977-3-1
Received: 27 May 2005

Accepted: 03 January 2006

This article is available from: http://www.particleandfibretoxicology.com/content/3/I/I

(C) 2006 Kocbach et al; licensee BioMed Central Ltd.

This is an Open Access article distributed under the terms of the Creative Commons Attribution License (http://creativecommons.org/licenses/by/2.0), which permits unrestricted use, distribution, and reproduction in any medium, provided the original work is properly cited.

\begin{abstract}
Background: Exposure to ambient particulate matter has been associated with a number of adverse health effects. Particle characteristics such as size, surface area and chemistry seem to influence the negative effects of particles. In this study, combustion particles from vehicle exhaust and wood smoke, currently used in biological experiments, were analysed with respect to microstructure and chemistry.
\end{abstract}

Methods: Vehicle exhaust particles were collected in a road tunnel during two seasons, with and without use of studded tires, whereas wood smoke was collected from a stove with single-stage combustion. Additionally, a reference diesel sample (SRM 2975) was analysed. The samples were characterised using transmission electron microscopy techniques (TEM/HRTEM, EELS and SAED). Furthermore, the elemental and organic carbon fractions were quantified using thermal optical transmission analysis and the content of selected PAHs was determined by gas chromatographymass spectrometry.

Results: Carbon aggregates, consisting of tens to thousands of spherical primary particles, were the only combustion particles identified in all samples using TEM. The tunnel samples also contained mineral particles originating from road abrasion. The geometric diameters of primary carbon particles from vehicle exhaust were found to be significantly smaller $(24 \pm 6 \mathrm{~nm})$ than for wood smoke $(3 \mathrm{I} \pm 7 \mathrm{~nm})$. Furthermore, HRTEM showed that primary particles from both sources exhibited a turbostratic microstructure, consisting of concentric carbon layers surrounding several nuclei in vehicle exhaust or a single nucleus in wood smoke. However, no differences were detected in the graphitic character of primary particles from the two sources using SAED and EELS. The total PAH content was higher for combustion particles from wood smoke as compared to vehicle exhaust, whereas no source difference was found for the ratio of organic to total carbon.

Conclusion: Combustion particles from vehicle exhaust and residential wood smoke differ in primary particle diameter, microstructure, and PAH content. Furthermore, the analysed samples seem suitable for assessing the influence of physicochemical characteristics of particles on biological responses. 


\section{Background}

Exposure to ambient particulate matter has been associated with a number of adverse health effects, including cardiopulmonary morbidity and mortality [1-3] and lung cancer mortality [2]. The mechanisms underlying the observed adverse effects and the responsible particle properties are still not well understood. Application of chemical and physical characterisation of particles in epidemiological studies have, however, linked particle properties like elemental and organic carbon content $[4,5]$ and surface area to mass [6], to negative health effects. Similarly, experimental studies have investigated the influence of particle characteristics on biological responses, and the inflammatory potential of several particle types has been found to increase with the particle surface area [7-9]. Recent reviews of the adverse effects of diesel exhaust particles associate both the carbon particle core and the adsorbed organic compounds with the observed immune responses $[10,11]$. Studies of inflammatory potential and oxidative stress, on the other hand, indicate that the organic component (content of OC or PAHs) is the responsible particle property [12-14]. Furthermore, studies of the mutagenic potential of urban particulate matter support the biologic plausibility of an association between particulate matter and lung cancer, and that a considerable portion of the mutagenic potential of urban particles is accounted for by PAHs $[15,16]$.

Combustion particles, generated during incomplete combustion of fossil fuels and biomass, consist of tens to thousands of primary carbon particles (diameters $\approx 20-50$ $\mathrm{nm})$, leading to a large surface area per mass. The primary particles of carbon aggregates may exhibit an internal turbostratic microstructure, consisting of a concentric arrangement of layer planes with a two-dimensional graphitic crystal structure, lacking the ordered stacking of graphite [17]. High resolution transmission electron microscopy allows for visualization of the 002 lattice fringes of the graphitic layer planes [18]. Turbostratic microstructure has been observed in the model particles carbon black and in particles from diesel exhaust and biomass combustion [17,19-22]. The microstructure of primary particles may give information of the processes involved in particle formation [19], and the particles ability to accumulate potentially reactive substances [23].

In Norway vehicle exhaust and residential wood smoke are the primary sources of particulate air pollution, accounting for more than $65 \%$ of the total emissions [24]. Detailed knowledge about particle size, morphology and chemical composition is important to understand the mechanisms by which particles affect human health. Particulate matter samples of vehicle exhaust and wood smoke for use in biological experiments were, therefore, collected. The objective of the study was to characterise and compare combustion particles from these two sources with respect to physical and chemical properties that may influence the biological potency of the particles. Analytical transmission electron microscopy techniques were used to analyse the geometric diameter and microstructure of primary carbon particles. The content of elemental and organic carbon was determined using thermal optical transmittance, and the samples were analysed for selected PAHs by gas chromatography with mass spectrometry (GC-MS).

\section{Methods \\ Sample collection}

Vehicle exhaust particles were collected in a motorway tunnel (Oslo, Norway) with a traffic load of approximately 40.000 vehicles/24 hrs. For the particle collection, twelve aerosol monitors (Millipore, MAWP 037 A0), loaded with polycarbonate filters with pore size $0.8 \mu \mathrm{m}$ and diameter $37 \mathrm{~mm}$, were connected to a pump through a specially designed manifold, resulting in an airflow of 6 $\mathrm{l} / \mathrm{min}$ through each monitor. The manifold was positioned two meters above the road level, and four meters from the passing traffic. In order to obtain sufficient quantities for the biological experiments, particles were sampled continuously for two weeks, scraped off the filters, and pooled. Samples were collected in two seasons, with and without contributions from cars using studded tires, and designated Tunnel St+ (April 2004) and St- (September 2004), respectively. Both samples contained contributions from cars, trucks and busses fuelled with diesel or gasoline.

A common Norwegian wood stove with single-stage combustion (Jøtul 3, Jøtul, Norway), placed in a laboratory at the Norwegian University of Science and Technology (NTNU, Trondheim, Norway), was used for the collection of wood smoke particles. Approximately $80 \%$ of the wood stoves in Norway are old stoves with similar combustion technology, and account for the majority of the particulate emissions from wood combustion. The wood smoke was cooled down by dilution with unfiltered air in a dilution tunnel, according to the Norwegian standard for testing of wood stoves [25]. Wood smoke particles were collected by isokinetic sampling (according to NS3058) on polycarbonate filters with pore size $0.8 \mu \mathrm{m}$ and diameter $102 \mathrm{~mm}$ (Millipore), with an airflow through the filter of $13.3 \mathrm{l} / \mathrm{min}$. Prior to particle collection, the stove was heated for $30 \mathrm{~min}$. Particles were sampled only during high-temperature combustion, obtained by a medium air supply and reloading of the oven approximately every 20 - $30 \mathrm{~min}$. The pump was turned off during the loading process, and turned on when the initially visible smoke from the pipe had ceased. To investigate a possible contribution from particles in the laboratory air to the wood smoke sample, the concentration of particulate matter in 
Table I: Results from transmission electron microscopy. The semi quantitative amounts of carbon aggregates and mineral particles (see text) and mean values with standard deviations for the geometric diameters of primary particles.

\begin{tabular}{lccc}
\hline Sample & Carbon aggregates & Mineral particles & Mean diameter $(\mathrm{nm})$ \\
\hline Tunnel St+ & + & ++ & $25 \pm 7$ \\
Tunnel St- & ++ & + & $24 \pm 6$ \\
Wood & +++ & - & $31 \pm 7 *$ \\
Diesel & +++ & - & $24 \pm 7$ \\
\hline
\end{tabular}

* Significantly higher mean value

the laboratory was measured using a Respicon ${ }^{\circledast}$ virtual impactor (TSI Incorporated, USA), and was found to be $69 \mu \mathrm{g} / \mathrm{m}^{3}$. This contribution was calculated to be smaller than $0.005 \%$, and considered negligible. Wood smoke particles were scraped off a total of 25 filters, pooled and designated Wood.

Diesel exhaust particles (SRM 2975, Industrial Forklift), were purchased from the National Institute of Standards and Technology (Gaithersburg, MD), and designated Diesel. Since Tunnel St+ and St- contained considerable amounts of road dust (mineral particles), Diesel was used as a reference for vehicle exhaust without mineral particles. The four samples (Tunnel St+, Tunnel St-, Wood and Diesel) were all collected as total suspended particulate matter (TSP).

\section{Electron microscopy}

The particles were dispersed in distilled water, and sonicated for $30 \mathrm{~min}$ in a water bath. Two $\mu \mathrm{l}$ of the solution was placed on a carbon filmed 200 mesh copper grid, or a microgrid with openings of approximately $0.1-4 \mu \mathrm{m}$. To avoid interference with the amorphous carbon film, HRTEM, SAED and EELS was performed on primary particles suspended over holes in the microgrid. The particle morphology and geometric diameters were examined by a TEM (JEM-1010, Jeol, Japan), operated at $100 \mathrm{keV}$. Since carbon aggregates were often linked in networks covering large areas, exact numbers of aggregates were not possible to count. Semi-quantification of the relative amounts of carbon aggregates and mineral particles was, therefore, used to describe specimens containing only $(+++)$, mostly $(++)$, or little $(+)$ of the respective particles (Table 1$)$. Geometric diameters of approximately 300 primary carbon particles were measured for each sample, in 10-15 carbon aggregates chosen on a random basis (method described in Kocbach et al. (2005) [26]). The microstructure of primary carbon particles was investigated using a HRTEM (JEOL-2010F, Jeol, Japan) operated at $200 \mathrm{keV}$, and attached to a parallel-detection EELS spectrometer (GIF; Digital Micrograph 2.5). Electron energy loss spectra were recorded in TEM imaging mode with an energy dispersion of $0.2 \mathrm{eV}$ per channel. Background subtraction of the spectra was performed using the Gatan EELS software EL/P 3.0. The heights of the $\pi^{*}$ and $\sigma^{*}$ peaks in the carbon $\mathrm{K}$ - edge were used to determine the $\pi^{*} / \sigma^{*}$ ratios, in order to investigate the graphitic character of the primary particles [27]. The $\pi^{*} / \sigma^{*}$ ratio was calculated for $8-13$ spectra from primary particles in each sample and for the amorphous carbon film.

\section{Carbon analysis}

The total carbon (TC) content of the samples was analysed by thermal optical transmittance, and divided into the organic (OC) and elemental (EC) carbon fractions. An instrument from Sunset Laboratories Inc (USA) was used for the analysis, according to the National Institute of Occupational Safety and Health (NIOSH) method 5040 [28]. The applied temperature steps during the first stage (pure He atmosphere) were $220^{\circ} \mathrm{C}(60 \mathrm{sec}), 360^{\circ} \mathrm{C}(60$ $\mathrm{sec}), 525^{\circ} \mathrm{C}(60 \mathrm{sec})$ and $850^{\circ} \mathrm{C}(90 \mathrm{sec})$, and during the second stage $\left(98 \% \mathrm{He}\right.$ and $\left.2 \% \mathrm{O}_{2}\right) 550^{\circ} \mathrm{C}(30 \mathrm{sec}), 650^{\circ} \mathrm{C}$ (30 sec), $720^{\circ} \mathrm{C}(30 \mathrm{sec}), 790^{\circ} \mathrm{C}(40 \mathrm{sec}), 820^{\circ} \mathrm{C}(30 \mathrm{sec})$, $860^{\circ} \mathrm{C}(20 \mathrm{sec})$ and $890^{\circ} \mathrm{C}(40 \mathrm{sec})$. The quartz filters $(1.5$ $\mathrm{cm}^{2}$ ) used for the analysis were heated prior to particle application, to minimise the carbon background level of the filters. For each sample, particles were applied to 3-5 quartz filters which were weighed before and after particle application, to determine the particle mass. An organic carbon contamination during particle application was determined to be $0.28 \pm 0.04 \mu \mathrm{g} \mathrm{C} / \mathrm{cm}^{2}$ by analysis of three filters. This was subtracted from the organic carbon levels.

\section{PAH analysis}

A total of 18 PAHs were selected for analysis, including the US Environmental Protection Agency PAH 16, which are priority PAHs based on concerns that they cause or might cause cancer in animals and humans. Additionally, two PAHs commonly measured in ambient air samples, Benzo(e)pyrene and 1-Methylphenanthrene, were included. These may be carcinogenic but the evidence is limited or inadequate [29]. The PAH content in Tunnel St+, Tunnel St- and Wood was analysed by GC-MS at the National Institute for Public Health and the Environment (RIVM, Bilthoven, the Netherlands). An aliquot $(1 \mathrm{ml})$ of internal standards (16 deuterated PAHs) and $50 \mathrm{ml}$ dichloromethane/isohexane (1:1) was added, and the compounds were released by sonication. After centrifugation the extract was concentrated by evaporation to dryness and redissolved in $1 \mathrm{ml}$ toluene. The extracts were 


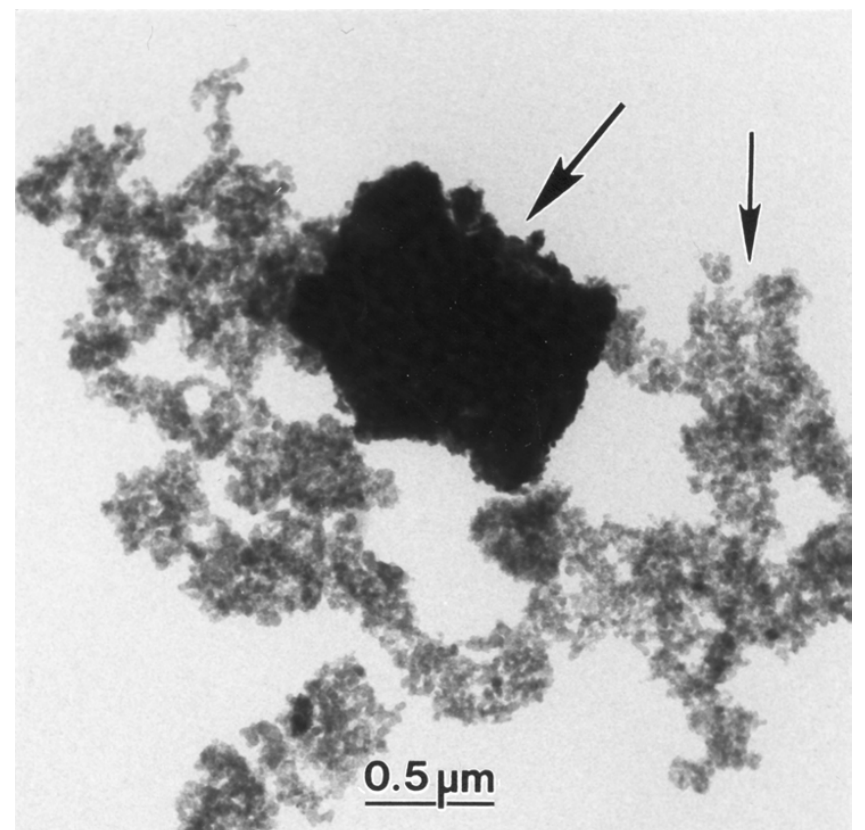

Figure I

Particle morphology. TEM micrograph of a tunnel sample showing a mineral particle (large arrow) and carbon aggregates (small arrow). then filtrated over a low-binding Durapore PVDF membrane $(0.22 \mu \mathrm{m})$ with a final extract volume of $1 \mathrm{ml}$. One $\mu \mathrm{l}$ was injected (splitless mode) at $290^{\circ} \mathrm{C}$ on a $30 \mathrm{~m}, 0.25$ mm WCOT DB-5MS column (film $0.1 \mu \mathrm{m}$ ). A column temperature programmed from $90-160-300^{\circ} \mathrm{C}$ was used, in a Fisons 8000 series gaschromatograph equipped with an Interscience Voyager mass-spectrometer with EI in SIR mode. Detection limits were approximately $0.1-0.7$ $\mathrm{ng} /$ extract. The method has been tested to give maximum yield for PAHs.

\section{Statistics}

All statistical analyses were performed in SPSS 12.0.1. Differences in mean primary particle diameters and carbon content were analysed using parametric tests (one way ANOVA, independent samples t-test), while differences in $\pi^{*} / \sigma^{*}$ ratios were analysed using non-parametric tests (Kruskal-Wallis, Mann-Whitney). Probability levels less than 0.05 were considered statistically significant. For multiple testing, the $p$-values were adjusted according to the Sequential Bonferroni approach [30].

\section{Results}

\section{Particle morphology (TEM)}

The collected tunnel samples contained carbon aggregates, consisting of tens to thousands of primary carbon particles, and mineral particles of arbitrary shape (Figure
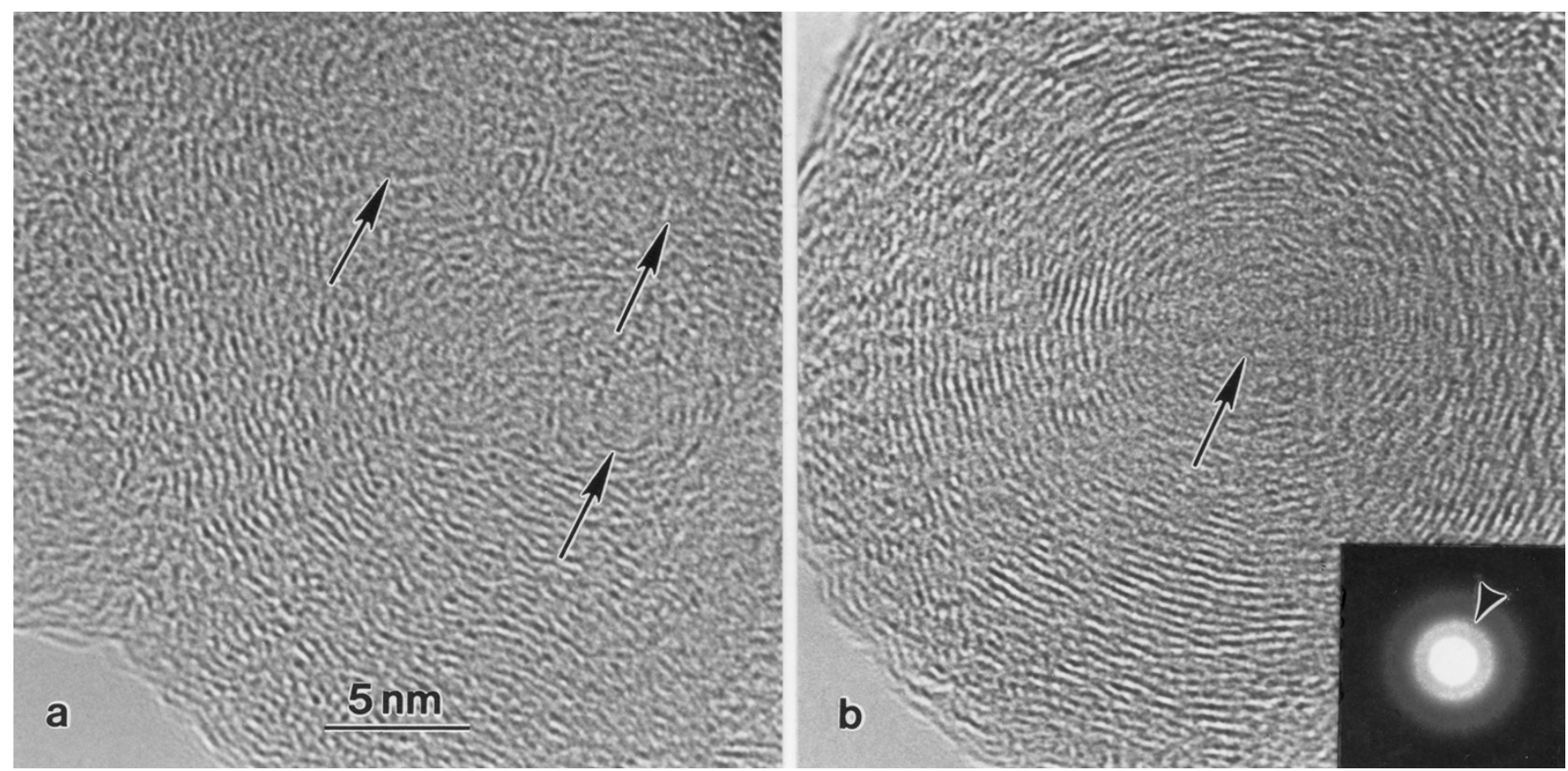

Figure 2

Turbostratic microstructure of primary carbon particles. TEM micrographs showing the turbostratic microstructures, consisting of concentric carbon layers surrounding a) several nuclei in vehicle exhaust (arrows), or b) a single nucleus in wood smoke (arrow). The inset shows a SAED pattern from a wood smoke particle. The arrowhead points at the ring corresponding to the 002 spacings in the turbostratic microstructure. 
1). In contrast, Wood and Diesel contained only carbon aggregates. As could be expected, Tunnel St+ contained more mineral particles relative to the amount of carbon aggregates, as opposed to Tunnel St- (Table 1). Moreover, Tunnel St+ contained larger sized mineral particles $(60 \%$ $>2 \mu \mathrm{m})$ as compared to Tunnel St- $(20 \%>2 \mu \mathrm{m})$. The size distributions of the geometric diameters of primary carbon particles were approximately normally distributed and monomodal for all samples (not shown). As seen in Table 1, the mean diameter for Wood was significantly larger than the mean values for the three vehicle exhaust samples (Tunnel St+, Tunnel St-, and Diesel). There were no significant differences between any of the vehicle exhaust samples.

\section{Microstructure of primary carbon particles}

Using HRTEM, a turbostratic microstructure consisting of concentric carbon layers surrounding either several nuclei or a single nucleus, was observed for primary particles in samples from both vehicle exhaust and wood smoke. In the vehicle exhaust samples, primary particles with several nuclei were observed most frequently (Figure 2a), in contrast to the wood smoke sample were only particles with one nucleus were found (Figure $2 \mathrm{~b}$ ). The observed turbostratic microstructure was confirmed by the presence of a 002 ring in the SAED patterns (inset in Figure 2b). Calculation of the interlayer distances from the diffraction patterns gave values between 0.38 and $0.40 \mathrm{~nm}$. No differences were, however, found between the samples.

To further investigate a possible difference in the graphitic character of primary particles from vehicle exhaust and wood smoke, the samples were analysed by EELS. The spectra from primary particles from both sources showed a higher ratio for the $\pi^{*}$ peak to the $\sigma^{*}$ peak than spectra from an amorphous carbon film (Figure $3 \mathrm{a}$ and $3 \mathrm{~b}$, respectively), indicating a graphitic structure [27]. The mean $\pi^{*} / \sigma^{*}$ ratios for primary particles in all four samples were significantly higher $(0.56 \pm 0.05-0.60 \pm 0.04)$ than for the carbon film $(0.47 \pm 0.05)$, but with no significant differences between the samples.

\section{Carbon analysis}

Total carbon (TC) was determined to estimate the relative content of carbonaceous and mineral particles in the samples. As seen from Table 2, the mean TC mass percentages differed significantly between the samples, except for Wood and Diesel. The large difference in TC percentages for Tunnel St+ and St- reflects the difference in mineral particle content as observed by TEM. Accordingly, the high TC percentages for Wood and Diesel reflect that these samples contain only carbon aggregates.

In Table 2, the ratio of organic to total carbon (OC/TC ratio) is given rather than the $\mathrm{EC} / \mathrm{TC}$ ratio, since the toxicity of carbonaceous particles seems to be more closely linked to the organic rather than the elemental fraction of the particles. The mean OC/TC ratios differed significantly between the samples, except for Tunnel St- and Wood. No source difference was found in OC/TC ratio, since the ratio for Wood was within the range of the three vehicle exhaust ratios. With respect to biological experiments, the mass percentage of organic carbon (Table 2), which differed significantly between all samples, is more relevant than the OC/TC ratio.

\section{PAH analysis}

To compare the PAH content in the samples, the sum of the 18 measured PAHs (Total PAH) is given for each sample in $\mathrm{ng} / \mathrm{mg}$ (Table 2). The Total PAH for Diesel is based on data from the Certificate of Analysis [31], and does not include measurements of Fluorene, Acenaphthene, Acenaphthylene and Naphthalene. As seen in Table 2, the Total PAH was considerably higher in Wood than in the vehicle exhaust samples. However, the TEM analyses and TC mass percentages showed that the tunnel samples contained significant amounts of mineral particles. To be able to compare the PAH content of the combustion particles in the tunnel samples, to that of Wood and Diesel (containing only combustion particles), the PAH content relative to the mass fraction of TC was calculated for all samples. This Adjusted PAH content (Table 2) was also considerably higher for Wood, compared to the tunnel samples, confirming that the observed source difference was not due to the mineral particle content.

Table 2: Results from chemical bulk analysis. The mean values with standard deviations for mass percentages of TC and OC, and $O C /$ TC ratio, as well as the Total PAH and Adjusted PAH (see text).

\begin{tabular}{lccccc}
\hline Sample & TC (\%) & OC/TC (\%) & OC (\%) & Total PAH (ng/mg) & Adjusted PAH (ng/mg) \\
\hline Tunnel St+ & $14.3 \pm 0.1$ & $65.1 \pm 3.1$ & $9.3 \pm 0.4$ & 73 & 510 \\
Tunnel St- & $51.0 \pm 3.8$ & $47.9 \pm 0.3^{*}$ & $24.4 \pm 2.0$ & 381 & 747 \\
Wood & $82.6 \pm 5.8^{*}$ & $42.7 \pm 4.4^{*}$ & $35.4 \pm 5.1$ & 9745 & 11797 \\
Dieselx & $80.0 \pm 5.1^{*}$ & $20.4 \pm 1.1$ & $16.3 \pm 1.2$ & 67 & 84
\end{tabular}

$\times$ The PAH sums for Diesel are based on data from the Certificate of Analysis (see text).

* Pairs of data where no significant differences were observed 

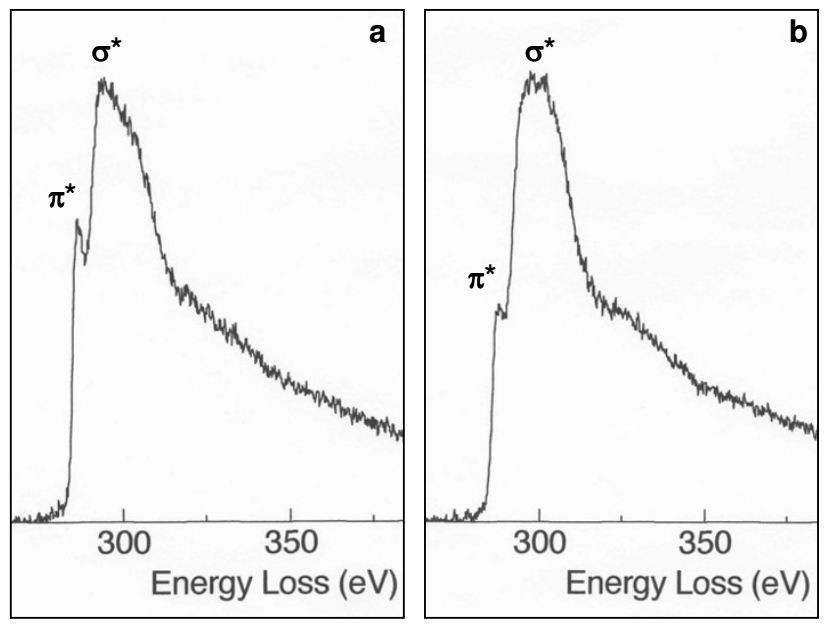

Figure 3

EELS spectra. The spectra show the $\pi^{*}$ and $\sigma^{*}$ peaks in the carbon K-edge for a) a primary carbon particle (wood smoke) and b) the amorphous carbon film.

The PAH profiles for the four samples, presented as a histogram in Figure 4, show levels of the single PAHs divided by the Total PAH. The profiles were found to be quite similar for Tunnel St+, Tunnel St- and Wood with Pyrene and Fluoranthene as the dominating compounds, whereas the profile for Diesel differed considerably having a higher content of Fluoranthene, Phenanthrene and Benzo [b]fluoranthene.

\section{Discussion}

Road traffic and residential wood combustion are the two principal sources of particulate air pollution in Norway. Differences in physical and chemical characteristics of combustion particles from these two sources may influence the severity of the health effects induced by inhalation of the particles. Since the samples analysed in the present study are also used to examine biological activity, the sampling sites and methods were chosen to provide large quantities. A vehicle exhaust sample without mineral particles (Diesel) was included in the study, since the biological effects of mineral particles may be higher than for carbonaceous particles in some biological systems [3234].

Carbon aggregates were the only combustion particles observed in all samples, in agreement with previous observations in ambient air source samples [26]. Additionally, mineral particles most likely originating from road abrasion were observed in the two tunnel samples. The higher mineral particle content observed in Tunnel St+ compared to Tunnel St- was probably due to the use of studded tires during the sampling period. In agreement with our previous study of low volume collection of ambi- ent air particles [26], the primary particle diameter in carbon aggregates from wood smoke was found to be significantly higher compared to vehicle exhaust. However, the diameters reported previously, were somewhat larger $(27 \pm 7 \mathrm{~nm}$ for vehicle exhaust and $38 \pm 11 \mathrm{~nm}$ for wood smoke), probably due to differences in TEM specimen preparations. In our previous study, carbon extraction replicas coated with a $15 \mathrm{~nm}$ carbon film, were prepared directly from the collection filters.

The turbostratic microstructure of primary particles in samples from mixed vehicle exhaust and residential wood smoke has not been described in the literature. The microstructure observed in the vehicle exhaust samples, however, with several nuclei surrounded by concentric carbon layers, resembles the turbostratic microstructure described for carbon black [17] and diesel exhaust [19]. The microstructure of a particle may give information about the processes involved in particle growth, condensation and coagulation $[19,35]$. The present results suggest that growth of wood smoke particles is dominated by condensation (one nucleus), while growth of vehicle exhaust particles involves a combination of coagulation and condensation (several nuclei).

The interlayer distances calculated from the SAED patterns were not found to differ between primary particles from vehicle exhaust and wood smoke, probably since the diffraction patterns were broad and diffuse, making an accurate measurement of the diameters difficult. The calculated interlayer distances are, however, in reasonable agreement with those reported for diesel exhaust particles, which range from $0.36 \mathrm{~nm}[23,36]$ to $0.383 \pm 0.025 \mathrm{~nm}$ [21]. A possible source difference in graphitic character was further investigated by EELS, as previously applied by Katrinak et al. (1992) [27] and Jaeger et al. (1999) [18], but no significant differences were found.

The low TC mass percentage observed for Tunnel St+ compared to Tunnel St-, is thought to be a consequence of the higher mineral particle content due to the use of studded tires. The OC/TC ratios measured by thermal optical transmittance, are reported to range from $8-85 \%$ for diesel vehicles [37-39] and 69-98\% for gasoline vehicles [38]. The OC/TC ratios presently measured for Tunnel St+ and St- (Table 2) are lower than those reported for gasoline. This may indicate a higher contribution from diesel than gasoline vehicles, which is in line with the higher relative contribution from diesel (88\%) compared to gasoline $(12 \%)$ vehicles, to the particulate vehicle emission estimates for Norway [24]. Incidentally, traffic counts in the road tunnel showed lower counts for long vehicles (> $5.5 \mathrm{~m}$, diesel vehicles) during the sampling of Tunnel St+ compared to Tunnel St- (Harald Granrud, Norwegian Public Roads Administration, personal communication). 


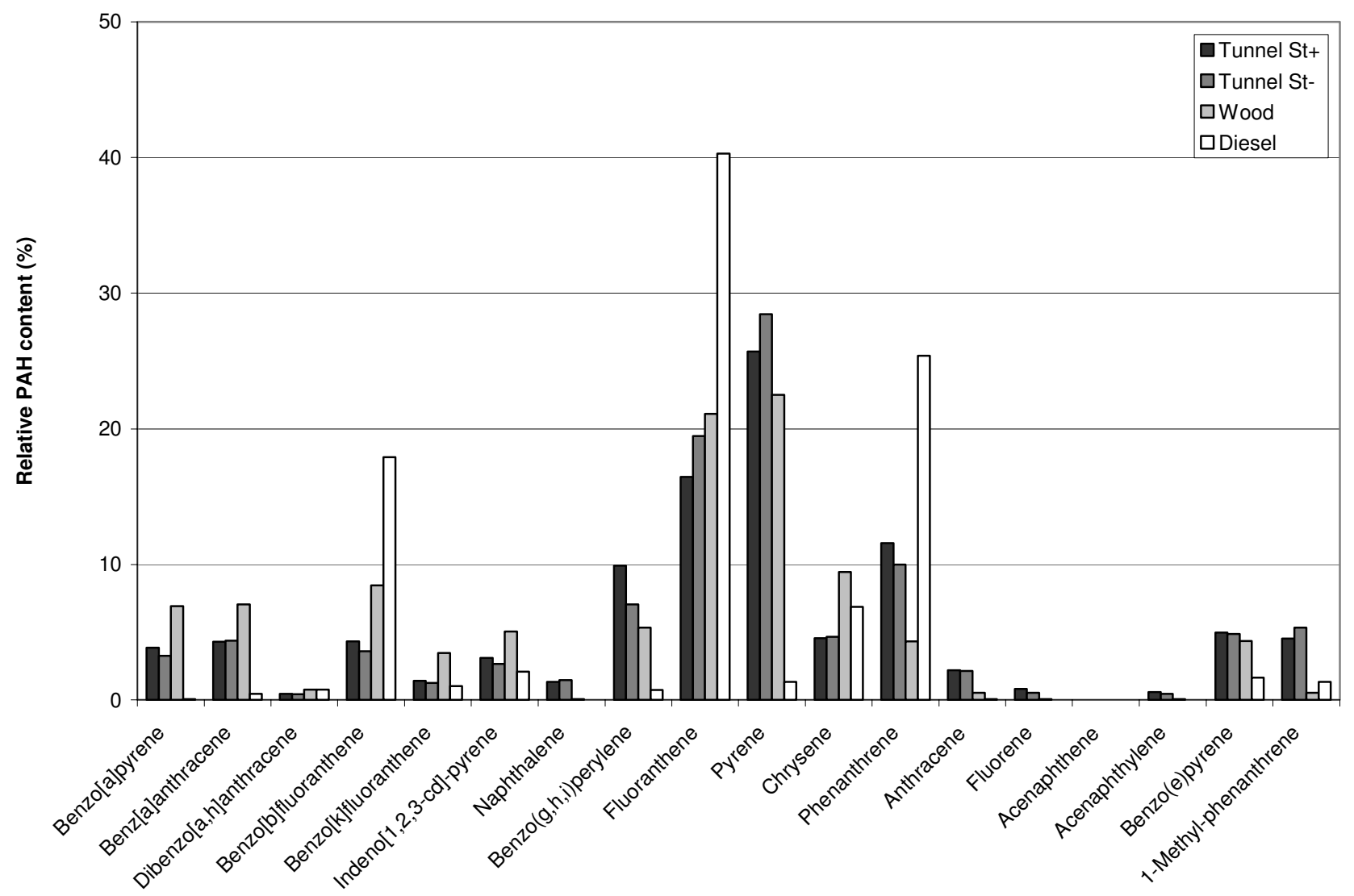

Figure 4

PAH profiles. The histogram shows the levels of single PAHs divided by Total PAH for the four samples (Tunnel St+, Tunnel St-, Wood and Diesel).

This may explain, in part, the difference in OC/TC ratio between the two tunnel samples. The wood smoke sample analysed, in the present study, has considerably lower OC/TC ratio $(42.7 \%)$ than reported for residential wood smoke in the literature $(80-98 \%)[38,40]$. A possible explanation is that Wood was collected during high-temperature combustion and did not contain substances from the devolatilization of the wood, while the samples analysed in the literature were collected during the entire burning cycle. Moreover, this may also explain why no source difference was found in OC/TC ratio in the present study, whereas the ratios reported for wood smoke in the literature $[38,40]$ are mostly in a higher range than for vehicle exhaust [37-39].

The PAH levels reported in the literature for source emissions are mostly given as ambient air concentrations (ng/ $\mathrm{m}^{3}$ ) or emission factors ( $\mathrm{ng} / \mathrm{km}$ or $\mathrm{ng} / \mathrm{kg}$ ), making a comparison with other data difficult. However, a recent study reported fractional mass abundances (ng/mg) of PAH for a variety of vehicle exhaust source samples [41] with the highest PAH content in emissions from gasoline cars (3420 and $6900 \mathrm{ng} / \mathrm{mg}$ ), and considerably lower values for diesel vehicles (273 and $444 \mathrm{ng} / \mathrm{mg}$ ) and road dust (0.61-2.2 ng/mg). Comparison of these data with the present results (Adjusted PAH, Table 2) suggests that the tunnel samples, after adjusting for total carbon, can be considered to be source specific samples for mixed vehicle exhaust.

The PAH profiles for the tunnel samples correspond well with some reported road dust profiles $[41,42]$. In contrast, Wood differs from all profiles reported in the literature, with a lower content of Phenanthrene and Anthrachene $[43,44]$ or Acenaphthylene and Naphthalene [45]. This may be due to sampling from combustion of different wood species and variable combustion conditions. Moreover, differences in sampling methods in the various studies may also influence the obtained profiles. Although some information about the carcinogenic and mutagenic potency of the analysed PAHs is available $[16,29,42,46,47]$, their relative potencies are not identi- 
fied. However, there is agreement in the literature that Benzo(a)pyrene is the most carcinogenic $\mathrm{PAH}$, and that several have been found to be mutagenic $[16,46]$. Since the PAH profiles for Wood and the tunnel samples were found to be similar, the higher content of PAHs in the wood smoke particles indicates a higher mutagenic potential compared to vehicle exhaust. The actual contribution from wood combustion to ambient particle concentrations is likely to vary considerably with location and season, and the human exposure may be lower than the emission estimates for wood combustion of $65 \%$ [24]. However, based on ambient air measurements in Elverum, Norway, the contribution from residential wood combustion to fine particulate carbon has been estimated to be $65 \%$ [48], confirming that residential wood combustion is indeed a very important source to particulate air pollution in Norway.

The present results suggest that combustion particles from vehicle exhaust are characterised by a larger surface area to mass and a lower content of organic carbon and PAHs, as compared to wood smoke particles. Studies using particles such as polystyrene, carbon black and $\mathrm{TiO}_{2}$, in vitro and in vivo, have demonstrated that the particle toxicity increases with surface area $[7-9,49,50]$. Moreover, a high content of organic carbon and PAHs has been associated with increased inflammatory and oxidative potential [1214]. Based on the literature it is, however, not possible to assess the relative influence of surface area and organic content on particle toxicity. Possible differences in the toxicity of combustion particles from vehicle exhaust and wood smoke could, therefore, not be determined based on the present results. In order to compare the toxicity of particles from the two sources, biological experiments need to be conducted.

Although the analysed wood sample is only representative for high temperature combustion, and the reference diesel sample for older cars, they both contain carbon aggregates only, and allow for comparison of combustion particles from the two sources. The four samples differ in particle composition (carbon aggregates/mineral particles), primary particle diameter, OC mass percentage and $\mathrm{PAH}$ content and profile, and are therefore considered suitable for assessing the influence of these characteristics on the biological potential of particles.

\section{Conclusion}

The TEM analyses showed that combustion particles from vehicle exhaust and wood smoke differ in geometric primary particle diameter and turbostratic microstructure, whereas no significant differences were found in graphitic character using EELS and SAED. The bulk chemical analyses did not show any clear source difference in OC/TC ratio, whereas the PAH content was found to be much higher in wood smoke as compared to vehicle exhaust. The relative toxicity of combustion particles from the two sources could not be determined based on the present results and the available literature. A higher mutagenic and carcinogenic potential of the wood smoke particles seems likely, however, in the light of the similar PAH profile but larger PAH content compared to vehicle exhaust. With respect to biological experiments, the analysed samples seem more suitable for assessing the importance of physicochemical characteristics for biological responses, than for comparing the biological potential of combustion particles from the two sources.

\section{Abbreviations}

ANOVA - analaysis of variance; EC - elemental carbon; EELS - electron energy loss spectroscopy; GC-MS - gas chromatography-mass spectrometry; HRTEM - high resolution electron microscopy; OC - organic carbon; PAH polycyclic aromatic hydrocarbon; SAED - selected area electron diffraction; SRM - standard reference material; TC - total carbon; TEM - transmission electron microscopy.

\section{Competing interests}

The author(s) declare that they have no competing interests.

\section{Authors' contributions}

AK designed and coordinated the experimental work of this study, collected the samples, prepared all specimens for electron microscopy and carbon analyses, performed TEM and participated in carbon analyses. Furthermore, AK processed all data including tables and figures, carried out the statistical analyses, interpreted the results, wrote and prepared the manuscript. YJL performed the HRTEM, SAED and EELS. KEY performed the carbon analyses. FRC was responsible for the PAH analyses and participated in writing of the manuscript. PES participated in study design and writing of the manuscript. EN participated in study design, supervised the experimental work, participated in interpretation of the results, and is a co-writer of the manuscript. All authors read and approved the final manuscript.

\section{Acknowledgements}

The present work was supported by a grant from The Norwegian Academy of Science and Letters and Statoil (VISTA). The authors acknowledge Jan Zahlin and Astri Grestad for technical assistance, and thank Mari Samuelsen and Berit B Aam for participation in the sample collection. Furthermore, we acknowledge Inge Saanum and Johan Hustad for their advice concerning the wood smoke sampling. We also thank Johan Taftø for valuable discussions concerning HRTEM and EELS, and Paul HB Fokkens for his assistance in the PAH analyses.

\section{References}

I. Kappos AD, Bruckmann P, Eikmann T, Englert N, Heinrich U, Hoppe P, Koch E, Krause GH, Kreyling WG, Rauchfuss K, Rombout P, 
Schulz-Klemp V, Thiel WR, Wichmann HE: Health effects of particles in ambient air. Int J Hyg Environ Health 2004, 207:399-407.

2. Pope III CA, Burnett RT, Thun MJ, Calle EE, Krewski D, Ito $K$ Thurston GD: Lung cancer, cardiopulmonary mortality, and long-term exposure to fine particulate air pollution. J Am Med Assoc 2002, 287: I| 32-I| I4I.

3. Schulz H, Harder V, Ibald-Mulli A, Khandoga A, Koenig W, Krombach F, Radykewicz R, Stampfl A, Thorand B, Peters A: Cardiovascular effects of fine and ultrafine particles. J Aerosol Med 2005, 18:1-22.

4. Mar TF, Norris GA, Koenig JQ, Larson TV: Associations between air pollution and mortality in Phoenix, 1995-1997. Environ Health Persp 2000, 108:347-353.

5. Metzger KB, Tolbert PE, Klein M, Peel JL, Flanders WD, Todd K, Mulholland JA, Ryan PB, Frumkin H: Ambient air pollution and cardiovascular emergency department visits. Epidemiology 2004, I 5:46-56.

6. Moshammer $\mathrm{H}, \mathrm{Neuberger} \mathrm{M}$ : The active surface of suspended particles as a predictor of lung function and pulmonary symptoms in Austrian school children. Atm Environ 2003, 37:1737-1744

7. Brown DM, Wilson MR, MacNee W, Stone V, Donaldson K: Sizedependent proinflammatory effects of ultrafine polystyrene particles: A role for surface area and oxidative stress in the enhanced activity of ultrafines. Toxicol Appl Pharmacol 200I, 175:191-199.

8. Hetland RB, Schwarze PE, Johansen BV, Myran T, Uthus N, Refsnes M: Silica-induced cytokine release from A549 cells: Importance of surface area versus size. Hum Exp Toxicol 200I, 20:46-55.

9. Murphy SAM, Berube KA, Richards RJ: Bioreactivity of carbon black and diesel exhaust particles to primary Clara and type II epithelial cell cultures. Occup Environ Med 1999, 56:8I3-8I9.

10. Ma JY, Ma JK: The dual effect of the particulate and organic components of diesel exhaust particles on the alteration of pulmonary immune/inflammatory responses and metabolic enzymes. J Environ Sci Health Part C Environ Carcinog Ecotoxicol Rev 2002, 20: $117-147$

II. Siegel PD, Saxena RK, Saxena QB, Ma JK, Ma JY, Yin XJ, Castranova $\mathrm{V}$, Al Humadi N, Lewis DM: Effect of diesel exhaust particulate (DEP) on immune responses: contributions of particulate versus organic soluble components. J Toxicol Environ Health $A$ 2004, 67:22|-23|.

12. Boland S, Baeza-Squiban A, Fournier T, Houcine O, Gendron MC, Chevrier M, Jouvenot G, Coste A, Aubier M, Marano F: Diese exhaust particles are taken up by human airway epithelial cells in vitro and alter cytokine production. Am J Physiol 1999, 276:L604-L6I3.

13. Boland S, Bonvallot V, Fournier T, Baeza-Squiban A, Aubier M, Marano F: Mechanisms of GM-CSF increase by diesel exhaust particles in human airway epithelial cells. Am J Physiol Lung Cell Mol Physiol 2000, 278:L25-L32.

14. Li N, Sioutas C, Cho A, Schmitz D, Misra C, Sempf J, Wang M, Oberley $\mathrm{T}$, Froines J, Nel A: Ultrafine particulate pollutants induce oxidative stress and mitochondrial damage. Environ Health Perspect 2003, III:455-460.

15. Hannigan MP, Cass GR, Penman BW, Crespi CL, Lafleur AL, Busby Jr WF, Thilly WG: Human cell mutagens in Los Angeles air. Environ Sci Technol 1997, 3 I:438-447.

16. Hannigan MP, Cass GR, Penman BW, Crespi CL, Lafleur AL, Busby Jr WF, Thilly WG, Simoneit BRT: Bioassay-directed chemical analysis of Los Angeles airborn particulate matter using a human cell mutagenicity assay. Environ Sci Technol 1998, 32:3502-35I4.

17. Heckman FA: Microstructure of carbon black. Rubber Chem Technol 1964, 37:1245-1298.

18. Jager C, Henning T, Schlogl R, Spillecke O: Spectral properties of carbon black. I Non-Cryst Solids 1999, 258:16I-179.

19. Ishiguro T, Takatori Y, Akihama K: Microstructure of diesel soot particles probed by electron microscopy: first observation of inner core and outer shell. Combust Flame 1997, 108:23I-234.

20. Palotas AB, Rainey LC, Sarofim AF, Vander Sande JB, Ciambelli P: Effect of oxidation on the microstructure of carbon blacks. Energy Fuels 1996, 10:254-259.

21. Palotas AB, Rainey LC, Feldermann CJ, Sarofim AF, Vander Sande JB: Soot morphology: an application of image analysis in high- resolution transmission electron microscopy. Miscrosc Res Tech 1996, 33:266-278.

22. Pósfai M, Gelencsér A, Simonics R, Arató K, Li J, Hobbs PV, Buseck PR: Atmospheric tar balls: particles from biomass and biofuel burning. J Geophys Res 2004, 109:1-9.

23. Berube KA, Jones TP, Williamson BJ, Winters C, Morgan AJ, Richards RJ: Physicochemical characterisation of diesel exhaust particles: Factors for assessing biological activity. Atm Environ 1999, 33:1599-1614.

24. Brunvoll F, Hoie H: Natural resources and the environment 20032003 [http://www.ssb.no/english/subjects/0l/sa nrm/arkiv/nrm2003/]. Oslo, Statistics Norway

25. 3058 NNS: Enclosed wood heaters. Smoke emission. 1994

26. Kocbach A, Johansen BV, Schwarze PE, Namork E: Analytical electron microscopy of combustion particles: a comparison of vehicle exhaust and wood smoke. Sci Total Environ 2005, 346:23I-243.

27. Katrinak KA, Rez P, Buseck PR: Structural variations in individual carbonaceous particles from an urban aerosol. Environ Sci Technol 1992, 26: 1967-1976.

28. National Institute of Occupational Safety and Health: Elemental carbon (diesel particulate): Method 5040. 1999 [http:// www.cdc.gov/niosh/nmam/pdfs/5040f3.pdf].

29. IARC: Polynuclear aromatic compounds, part I: chemical, environmental and experimental data. Lyon, International Agency for Research on Cancer; 1983.

30. Quinn GP, Keough MJ: Multiple testing. In Experimental design and data analysis for biologists Edited by: Quinn GP and Keough MJ. Cambridge, University Press; 2002:48-50.

31. National Institute of Standards and Technology: Certificate of analysis. Standard reference material $® 2975$. Diesel particulate matter (Industrial forklift). 2000 [https://srmors.nist.gov/certifi cates/view cert2gif.cfm?certificate=2975].

32. De Berardis B, Balduzzi M, Diociaiuti M, Paoletti L: Differences in the biological activity of two PM3.3 components: carbonaceous and silica particles. Ann lst Super Sanita 2003, 39:419-423.

33. Hetland RB, Refsnes M, Myran T, Johansen BV, Uthus N, Schwarze PE: Mineral and/or metal content as critical determinants of particle-induced release of IL-6 and IL-8 from A549 cells. J Toxicol Environ Health A 2000, 60:47-65.

34. Pozzi R, De Berardis B, Paoletti L, Guastadisegni C: Inflammatory mediators induced by coarse (PM2.5-10) and fine (PM2.5) urban air particles in RAW 264.7 cells. Toxicology 2003, 183:243-254.

35. Lighty JS, Veranth JM, Sarofim AF: Combustion aerosols: factors governing their size and composition and implications to human health. J Air Waste Manage Assoc 2000, 50:1565-16/8.

36. Ishiguro T, Suzuki N, Fujitani $\mathrm{Y}$, Morimoto H: Microstructural changes of diesel soot during oxidation. Combust Flame 1991, 85:1-6.

37. Alander TJA, Leskinen AP, Raunemaa TM, Rantanen L: Characterization of diesel particles: effects of fuel reformulation, exhaust aftertreatment, and engine operation on particle carbon composition and volatility. Environ Sci Technol 2004, 38:2707-27|4.

38. Schauer J]: Evaluation of elemental carbon as a marker for diesel particulate matter. J Expo Anal Environ Epidemiol 2003, 13:443-453.

39. Singh P, DeMarini DM, Dick CA, Tabor DG, Ryan JV, Linak WP Kobayashi T, Gilmour MI: Sample characterization of automobile and forklift diesel exhaust particles and comparative pulmonary toxicity in mice. Environ Health Perspect 2004, I | 2:820-825

40. Tesfaigzi Y, Singh SP, Foster JE, Kubatko J, Barr EB, Fine PM, McDonald JD, Hahn FF, Mauderly JL: Health effects of subchronic exposure to low levels of wood smoke in rats. Toxicol Sci 2002, 65:115-125.

41. Manoli E, Kouras A, Samara C: Profile analysis of ambient and source emitted particle-bound polycyclic aromatic hydrocarbons from three sites in northern Greece. Chemosphere 2004, 56:867-878.

42. Nielsen T, Jorgensen HE, Larsen JC, Poulsen M: City air pollution of polycyclic aromatic hydrocarbons and other mutagens: occurrence, sources and health effects. Sci Total Environ 1996, | 89- | 90:4|-49. 
43. Hedberg E, Kristensson A, Ohlsson M, Johansson C, Johansson PA, Swietlicki E, Vesely V, Wideqvist U, Westerholm R: Chemical and physical characterization of emissions from birch wood combustion in a wood stove. Atm Environ 2002, 36:4823-4837.

44. Smith DJT, Harrison RM: Polycyclic aromatic hydrocarbons in atmospheric particles. In Atmospheric Particles Edited by: Harrison RM and Van Grieken R. Chichester, John Wiley \& Sons Ltd.; 1998:253-294.

45. Khalili NR, Scheff PA, Holsen TM: PAH source fingerprints for coke ovens, diesel and, gasoline engines, highway tunnels, and wood combustion emissions. Atm Environ 1995, 29:533-542.

46. Durant JL, Busby Jr WF, Lafleur AL, Penman BW, Crespi CL: Human cell mutagenicity of oxygenated, nitrated and unsubstituted polycyclic aromatic hydrocarbons associated with urban aerosols. Mutat Res 1996, 37 I: 123-157.

47. IARC: Some traditional herbal medicines, some mycotoxins, naphthalene and styrene. Lyon, International Agency for Research on Cancer; 2002.

48. Ramdahl T, Schjoldager J, Currie LA, Hanssen JE, Moller M, Klouda GA, Alfheim I: Ambient impact of residential wood combustion in Elverum, Norway. Sci Total Environ 1984, 36:81-90.

49. Donaldson K, Brown D, Clouter A, Duffin R, MacNee W, Renwick L, Tran L, Stone $\mathrm{V}$ : The pulmonary toxicology of ultrafine particles. J Aerosol Med 2002, 15:213-220.

50. Höhr D, Steinfartz Y, Schins RPF, Knaapen AM, Martra G, Fubini B, Borm PJA: The surface area rahter than the surface coating determines the acute inflammatory response after instillation of fine and ultrafine TiO2 in the rat. Int J Hyg Environ Health 2002, 205:239-244.

Publish with Bio Med Central and every scientist can read your work free of charge

"BioMed Central will be the most significant development for disseminating the results of biomedical research in our lifetime. "

Sir Paul Nurse, Cancer Research UK

Your research papers will be:

- available free of charge to the entire biomedical community

- peer reviewed and published immediately upon acceptance

- cited in PubMed and archived on PubMed Central

- yours - you keep the copyright

Submit your manuscript here:

http://www.biomedcentral.com/info/publishing_adv.asp
BiolMedcentral 